\title{
TEORI KEAGENAN DALAM PERSPEKTIF ISLAM
}

\author{
Achmad Uzaimi (achmad_uzaimi@umrah.ac.id) \\ Fakultas Ekonomi Universitas Maritim Raja Ali Haji
}

\begin{abstract}
The agency theory is a reference that has been widely used in accounting studies. But there is a fundamental difference between the assumptions used and the reality of Islamic values. Islam directs the agreement between the owner and the agent to a trusting relationship driven by a fraternal spirit based on the Qur'an and the Hadith. Principals and agents carry out their responsibilities by prioritizing tawakkal rather than their intellect, carrying on noble character in the execution of agreed contracts.

Keyword: Teori keagenan, tawakkal, akhlak, biaya keagenan
\end{abstract}

\section{PENDAHULUAN}

Jensen dan Meckling (1976) menggarisbawahi tiga teori, yang selanjutnya menjadi referensi pengembangan riset akuntansi seluruh dunia yaitu 1) teori hak atas kekayaan 2) keagenan dan 3) teori keuangan untuk mengembangkan teori struktur kepemilikan perusahaan. Teori-teori ini memberikan penerangan yang lebih jelas tentang definisi perusahaan (firm), pemisahan kepemilikan dan pengendalian (separation of ownership and control), social responsibility, definisi fungsi objektif korporat (corporate objective function).

Meskipun ketiganya dibahas dalam artikel tersebut namun yang paling menonjol dan banyak menjadi referensi riset akuntansi adalah teori keagenan. Didefinisikan bahwa hubungan agensi sebagai kontrak di mana satu atau lebih orang (principal) melibatkan orang lain (agen) untuk melakukan beberapa layanan yang mengatasnamakan mereka dan melibatkan pendelegasian beberapa wewenang pengambilan keputusan kepada agen. (Jensen dan Meckling, 1976)

Jika kedua belah pihak merupakan pelaku maksimalisasi utilitas (maximizers utility), merupakan alasan untuk bisa dipercayai bahwa agen dalam bertindak tidak akan selalu demi kepentingan terbaik principal. Sementara principal dapat membatasi divergensi tersebut demi kepentingannya, dengan menetapkan insentif yang sesuai bagi agen dan dengan menimbulkan biaya monitoring yang dirancang untuk membatasi aktivitas agen yang menyimpang. Selain itu dalam beberapa situasi, ia akan membayar agen untuk mengeluarkan sumber daya (biaya ikatan) untuk menjamin bahwa dia tidak akan mengambil tindakan tertentu yang akan merugikan prinsipal atau untuk memastikan bahwa principal akan diberi kompensasi jika dia melakukan tindakan tersebut (Jensen \& Meckling, 1976).

Namun, umumnya tidak mungkin bagi principal maupun agen dapat memastikan bahwa agen akan membuat keputusan yang optimal dari sudut pandang principal dengan biaya nol. Dalam kebanyakan hubungan keagenan, prinsipal dan agen akan menanggung biaya monitoring dan pengikatan yang positif (nonpecuniary and pecaribary). Di samping itu akan terjadi perbedaan antara keputusan agen dan keputusan yang akan memaksimalkan kesejahteraan prinsipal. Nilai yang setara dengan pengurangan kesejahteraan prinsipal sebagai akibat dari perbedaan ini juga merupakan biaya keagenan, dan kita mengacu pada biaya terakhir ini sebagai "kerugian residual" sehingga dapat ditentukan biaya agensi merupakan jumlah dari 1) 
pengeluaran monitoring/pengendalian oleh prinsipal, 2) pengeluaran obligasi oleh agen, 3) kerugian residual. Pandangan ini dikenal dengan teori keagenan (agency theory).

Dengan kata lain teori keagenan mempunyai asumsi bahwa individu dimotivasi hanya oleh kepentingan pribadi (self interest). Apabila terjadi perilaku kooperatif dimana ada usaha memaksimalkan kesejahteraan kelompok (bersama-sama) maka hal ini menjadi tidak konsisten dengan teori keagenan. Teori keagenan bisa terjadi apabila kepentingan pribadi (tanpa paksaan) tidak konsisten dengan perilaku kooperatif kelompok atau dengan kata lain dapat menyebabkan perilaku kooperatif kelompok tidak efisien. (Baiman, 1990)

\section{LANDASAN TORI}

\section{Karakteristik Teori Keagenan}

Dalam teori keagenan di atas dapat ditemukan beberapa karakteristik antara lain principal dan agen diasumsikan bertindak secara rasional, sama-sama bertujuan memaksimalisasi utilitas atau kepentingan pribadi dan secara umum seakan-akan saling memaksimalkan keuntungan pihak lain (prinispal-agen) dan tidak terdapat perilaku kooperatif kelompok. Konsekuensi dari semua itu timbulnya biaya keagenan (agency cost). Principal dan agen bertindak secara rasional maksudnya adalah bahwa merupakan suatu hal yang lazim jika principal bertindak untuk memperoleh keuntungan dari setiap rupiah yang diinvestasikannya dengan cara memaksimalkan monitoring setiap tindakan yang dilakukan oleh agen. Dengan kata lain tidak dapat mentolerir sekecil apapun kesalahan yang dilakukan oleh agen yang menyebabkan kerugian investasi. Sebaliknya agen tidak akan melakukan hal yang sebenarnya terbaik yang dimilikinya untuk memberikan keuntungan bagi principal. Namun apa yang dilakukannya tidak lebih dari bagaimana dia juga bisa memperoleh keuntungan besar dari pengorbanan yang seadanya (risk and work averse). (Baiman, 1990).

Teori ini ketidakpercayaan satu sama lain diakui sebagai perilaku yang biasa dalam berbisnis. Perilaku kooperatif (saling menguntungkan tanpa paksaan) akan menjadi inkonsisten. Keseluruhan ini pada akhirnya mengarahkan (drive) masing-masing pihak menambah instrument pekerjaan agar dapat lebih meyakinkan bahwa perjanjian kontrak tidak merugikan. Dengan kata lain kontrak saling percaya itu dibuat untuk saling tidak percaya.

\section{Kerjasama Dalam Persepktif Islam (Muamalah Tijarah)}

Dalam bahasan konsepsi kerjasama kontraktual, Islam memiliki perspektif yang berbeda dengan pandangan barat dan mendasarkan kerjasama pada sikap amanah (trust), tanggungjawab masing-masing pihak dan tawakal kepada Allah Subhanahu wata'ala (Isgiyarta, 2010). Hal ini jelas bahwa muamalah merupakan dimensi islam yang lain disamping iman (tauhid), ibadah (ubudiah), kehidupan social kemasyarakat (muasyarat) dan budi pekerti (akhlak). Maksud dilakukannya muamalah adalah agar kehidupan islami dalam jual beli, perjanjian/ kontraktual dapat direalisasikan dalam kehidupan nyata. Dalam melakukan apa saja haruslah mendasarkan pada iman kepada Allah dan yang tidak dapat ditangkap oleh panca indra (ghaib).

Iman kepada yang ghaib adalah beriman kepada Allah Ta'ala, kepada semua hal ghaib dan kepada semua yang dikhabarkan oleh Rasulullah salallahu alaihi wasallam tanpa melihatnya secara langsung, karena percaya dan membenarkan Nabi salallahu alaihi wasallam. Sekaligus mengsampingkan kesenangan-kesenangan sementara, penglihatan zahir manusia ataupun pembuktian secara fisik karena hal tersebut telah dikhabarkan oleh Rasulullah salallahu alaihi wasallam. (Kandahlawi, 2006) 
Kehidupan Islam mendasarkan pada wahyu ilahi (alquran) dengan contoh implementasi oleh Rasulullah salallahualaihi wasallam dan para sahabat Radiallahu anhum. Menerapkan alquran dengan mencontoh kehidupan salafussoleh ${ }^{1}$ mengurangi terjadinya bias dalam penerapan hukum dan adab-adab dalam islam. Hal ini karena Allah subhanallahu wata'ala berfirman:

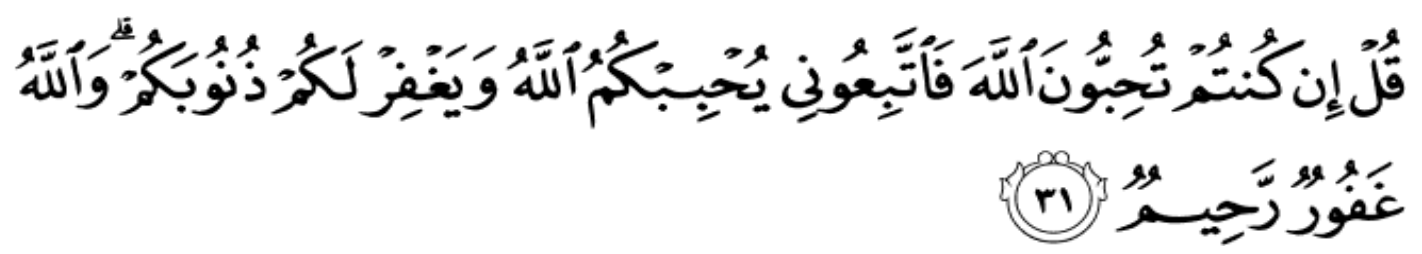

Artinya:

Katakanlah: "Jika kamu (benar-benar) mencintai Allah, ikutilah aku, niscaya Allah mengasihi dan mengampuni dosa-dosamu". Allah Maha Pengampun lagi Maha Penyayang (QS. Ali Imran, ayat 31)

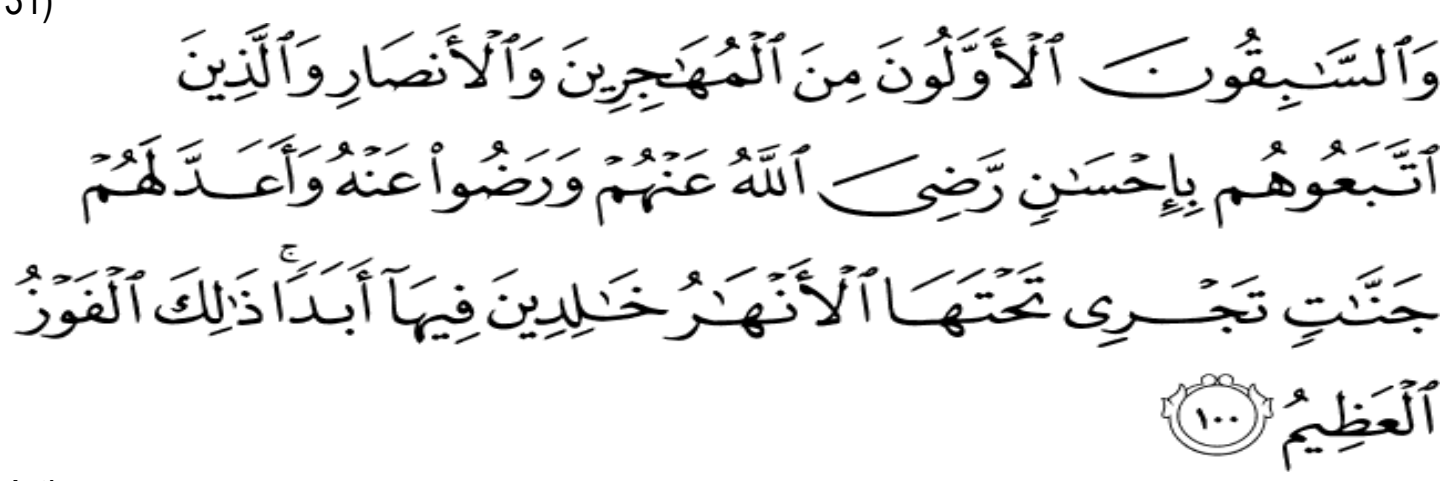

Artinya:

Orang-orang yang terdahulu lagi yang pertama-tama (masuk Islam) dari golongan muhajirin dan anshar dan orang-orang yang mengikuti mereka dengan baik, Allah ridha kepada mereka dan merekapun ridha kepada Allah dan Allah menyediakan bagi mereka surga-surga yang mengalir sungai-sungai di dalamnya selama-lamanya. Mereka kekal di dalamnya. Itulah kemenangan yang besar. (QS At Taubah ayat 100)

Artinya:

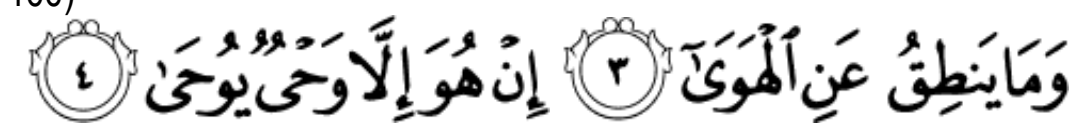

Dan tiadalah yang diucapkannya itu menurut kemauan hawa nafsunya. Ucapannya itu tiada lain hanyalah wahyu yang diwahyukan (kepadanya). (QS An Najm. Ayat 3-4)

Menurut ayat pertama di atas bahwa cara untuk mewujudkan keyakinan terhadap Allah Subhanallahu wata'ala hanya dengan mengikuti cara Rasulullah salallahualaihi wasallam. Pada ayat kedua Allah subhanallahu wata'ala menyatakan keridhoanNya atas para sahabat radiallahuanhum baik dari kalangan Anshar maupun Muhajirin ${ }^{2}$ atas apa-apa yang mereka perbuat. Sedangkan ayat ketiga merupakan penegasan bahwa apa yang dilakukan oleh Rasulullah salallahualaihi wasallam bukan merupakan kehendak hawa nafsu beliau tetapi apaapa yang diperintahkan Allah Subhanallahu wata'ala.

\footnotetext{
1 Salafussoleh adalah era Rasulullah salallahualaihi wasallam hidup bersama para sahabat dimana peradaban islam dijalankan sepenuhnya.

2 Kaum Anshar merupakan orang yang pertama kali menerima dan masuk islam yang tinggal di Madinah. Kaum Muhajirin adalah orang-orang yang mengikuti Nabi salallahu alaihi wassalam pindah dari Mekah ke Masdinah
} 
Sehingga dalam menjalankan syariat Islam yang diperintahkan Allah tidak akan baik jika tidak dilakukan dengan cara-cara yang telah dilakukan oleh orang-orang yang dicintai dan diridhoi oleh Allah Subhanahu wata'ala.

\section{Muamalah Bukan Hanya Untuk Kepentingan Zahir}

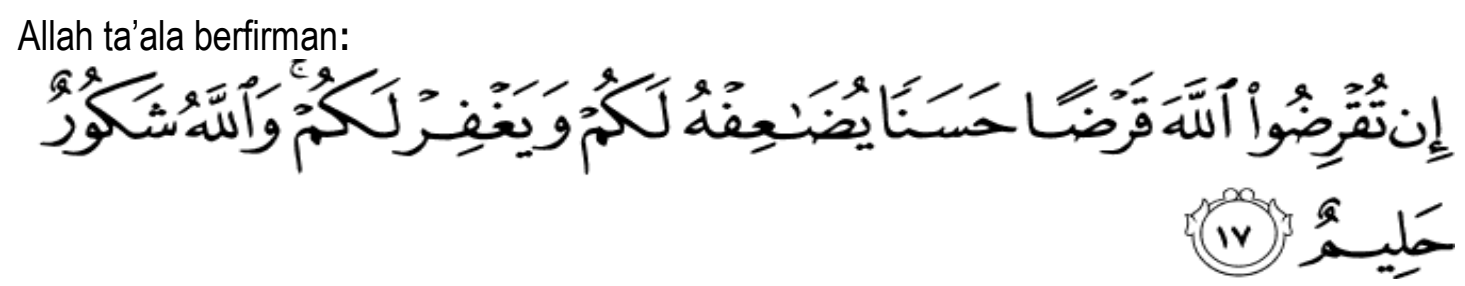

Jika kamu meminjamkan kepada Allah pinjaman yang baik, niscaya Allah melipat gandakan balasannya kepadamu dan mengampuni kamu. Dan Allah Maha Pembalas Jasa lagi Maha Penyantun. (QS At Taghabun ayat 17) Dalam ayat ini dijelaskan bahwa apabila kita bertransaksi (qardhan hasanah) dengan Allah berupa infak, sedekah maka Allah menjanjikan untuk kita pahala dan diampuni dosa yang sifatnya pasti. Bertransaksi dengan Allah merupakan bentuk ibadah yang disertai dengan keyakinan mendapatkan janji-janji Allah bukan sekedar perbelanjaan yang hanya bermanfaat untuk kehidupan di dunia tetapi juga di akhirat.

Dari Abu Hurairah radiallahuanhu, ia berkata, Rasulullah salallahualaihi wasallam bersabda, "Barangsiapa yang menerima pembatalan jual beli dari seorang muslim, Allah akan menghapus kesalahannya" (HR Abu Dawud)

\section{Keterangan}

Maksudnya: dua orang berjual beli, lalu salah seorang di antara mereka merasa kecewa. Kemudian ia meminta agar jual-beli itu dibatalkan dan orang yang satunya menerima pembatalan jual-beli tersebut. Maka orang yang menerima pembatalan tersebut Allah akan menghapuskan dosa-dosanya (Badzlul Majhud). Dalam hadist ini dijelaskan bahwa berjual beli bukan berorientasi mencari laba namun lebih bersifat pemenuhan kebutuhan orang lain sekaligus menunaikan hak-haknya. Harkat dan martabat orang lain lebih diutamakan daripada mencari keuntungan yang sifatnya sementara dan nilainya tidak seberapa jika dibandingkan luasnya karunia Allah. Untuk urusan keduniaan saja jika dilakukan dengan niat menyenangkan Allah maka Allah akan membalasnya dengana sesuatu yang bermanfaat di kehidupan setelah kematian.

Muslim meriwayatkan dalam Shahih-nya dari Abu Hurairah dari Nabi berkata, "Ketika seorang laki-laki berada di tempat yang sunyi, dia mendengar suara awan, 'Siramilah kebun fulan.' Lalu awan itu menjauh dan menumpahkan airnya di tanah dengan bebatuan hitam. Ternyata ada saluran air yang telah dipenuhi oleh seluruh air itu. Laki-laki itu menelusuri jalannya air. Ternyata ada seorang laki-laki yang berdiri di kebunnya, dia mengalirkan air dengan cangkulnya. Dia bertanya, 'Wahai hamba Allah, siapa namamu?' Dia menjawab, 'Fulan.' Nama yang didengarnya dari suara di awan. Dia berkata, 'Wahai hamba Allah mengapa kamu bertanya tentang namaku?' Dia menjawab, 'Sesungguhnya aku mendengar suara di awan di mana airnya adalah ini. Suara itu berkata, 'Siramilah kebun fulan.' Yaitu, namamu. Apa yang kamu lakukan padanya?' Dia menjawab, 'Karena kamu mengatakan itu, maka aku melihat hasil kebunku. Sepertiganya aku sedekahkan, sepertiga lagi aku makan bersama keluargaku, dan sepertiga sisanya aku kembalikan kepadanya.

Dalam riwayat ini dijelaskan bagaiamana seorang (Bani Israel) yang membelanjakan hartanya sesuai yang disenangi oleh Allah. Hal memberikan paparan yang jelas juga tentang 
berapa sebenarnya kebutuhan manusia tersebut. Apa yang dihasilkan tidaklah semua miliknya namun ada hak-hak yang harus ditunaikan. Apabila ini dilaksanakan dengan niat menyenangkan Allah pastilah akan dibalas baik didunia ini maupun di akhirat nanti.

Dalam bermuamalah Rasulullah salallahualaihi wasallam memerintahkan para sahabat radiallahuanhum untuk menjaga adab-adab dalam bekerjasama (principal-agen). Sewaktu sahabat Muhajirin baru pindah ke Madinah maka sahabat Anshar berdialog dengan Rasulullah salallahualaihi wasallam

Yazid bin Asham Radiallauanhu berkata bahwa kaum anshar berkata kepada Rasulullah salallahualaihi wasallam. "Bagilah tanah-tanah kami yang separuh untuk kaum Muhajirin". Tetapi Rasulullah salallahualaihi wasallam tidak menerimanya, bahkan bersabda, "Hendaknya orangorang ini (Muhajirin) yang bercocok tanam dan hasilnya dibagi". "Dengan demikian kalian dibantu oleh mereka dan mereka juga dapat bantuan dari tanah kalian". (Kitab Durul Mansur). Islam mengakui adanya kepemilikan dalam harta (property right) dan pengelolaan oleh pihak lain (agent). Namun dalam hal hasil dibagi sesuai kesepakatan (contract). Kerjasama yang diajarkan di sini adalah kerja sama yang saling menguuntungkan yang didasarkan pada kasih saying dan saling percaya. Di sini juga dapat diamati bahwa dalam hal praktik tijarah muamalah, Rasulullah salallahualaihi wasallam sendiri terlibat dalam mengajarkan cara kerjasama yang baik dan benar. Dalam arti Rasulullah salallahualaihi wasallam bukan hanya sebagai pengamat praktik muamalah namun terlibat langsung mengarahkan dan mengatur.

\section{Kewajiban Pemilik}

Hak agen merupakan kewajiban yang harus dipenuhi oleh prinsipal atau pemilik. Beberapa kewajiban yang harus dipenuhi oleh principal terhadap agen diantaranya adalah:

Pertama, Islam memposisikan agen sebagaimana saudara sendiri bagi prinsipal. Dari Abu Dzar radiallahuanhu, Nabi salallahualaihi wasallam bersabda: "Saudara kalian adalah budak kalian. Allah jadikan mereka di bawah kekuasaan kalian." (HR. Bukhari) meskipun hadits ini menyebutkan budak bagi sebutan bawahan namun ulama sepakat bahwa hal ini dapat juga berarti bawahan, orang kepercayaan yang dalam pekerjaannya terikat oleh janji-janji. Nabi salallahualaihi wasallam menyebut buruh (agen) sebagaimana saudara majikan (principal) agar derajat mereka setara dengan saudara, sehingga akan memperlakukannnya dengan baik.

Kedua, seorang principal tidak boleh memberikan tugas pekerjaan kepada agen yang berlebihan, tidak memberikan upah sesuai dengan yang disepakati, menekan untuk melakukan pekerjaan yang berlebihan dan melewati waktu kerja. Rasulullah SAW melarang memberikan beban tugas kepada agen melebihi kemampuannya. Jikapun terpaksa itu harus dilakukan, beliau perintahkan agar sang principal turut membantunya. Kecuali ada kesepakatan dengan membayar kelebihan beban yang tidak ada dalam kesepakatan awal. Dalam hadis Abu Dzar radiallahuanhu, Nabi salallahualaihi wasallam bersabda: "Janganlah kalian membebani mereka (pekerja), dan jika kalian memberikan tugas kepada mereka, bantulah mereka." (HR. Bukhari)

Ketiga, seorang principal harus memperhatikan dan mengutamakan pemberian upah/gaji bagi agen. Nabi salallahualaihi wasallam mewajibkan para prinsipal untuk memberikan gaji pegawainya tepat waktu, tanpa dikurangi sedikit pun. Dari Abdullah bin Umar radiallahuanhu, Nabi salallahualaihi wasallam bersabda: "Berikanlah upah pekerja (buruh), sebelum kering keringatnya." (HR. Ibn Majah).

Rasulullah sangat memperhatikan penghargaan terhadap seorang pekerja. Masalah upah merupakan hal yang terpenting untuk didahulukan. Dengan nilai keadilan dalam Islam, maka 
bagaimana seorang pekerja agen merasa cukup dengan upah yang diterimanya dan upah itu sebanding dengan kontribusi yang telah mereka berikan kepada majikan (perusahaan).

Keempat, dianjurkan memperhatikan kesejahteraan para buruh (agen). Misalnya tentang kebutuhan akan pernikahan, keluarga, rumah, pendidikan dan kebutuhan lain untuk meningkatkan kompetensi dan kualitas pekerjanya, sehingga para buruh merasa kehidupannya tercukupi dan lebih tenang serta tentram hatinya.

\section{Kewajiban Pengelola}

Jika hak-hak agen yang menjadi kewajiban para principal atau pemilik ditunaikan, maka dengan sendirinya para agen akan memenuhi kewajibannya sebagai seorang pekerja, diantaranya: Pertama, agen harus melakukan pekerjaan dengan jujur, ikhlas dan berkualitas. Mereka bekerja secara optimal sehingga produktivitasnya meningkat sehingga akan meningkatkan hasil bagi pemilik/perusahaan. Dampaknya, kesejahteraan pekerja pun akan meningkat pula. Rasulullah saw bersabda : "Sesungguhnya Allah mengasihi ketika salah seorang dari kalian yang melakukan sesuatu pekerjaan maka ia melakukannya dengan baik,"

Kedua, para buruh hendaknya menghindari perbuatan penipuan dan pengkhianatan selama bekerja dalam keadaan bagaimanapun juga. Seperti korupsi waktu, barang atau asset berapapun nilainya. Allah subhanallahu wata'ala berfirman dalam Al-Qur'an

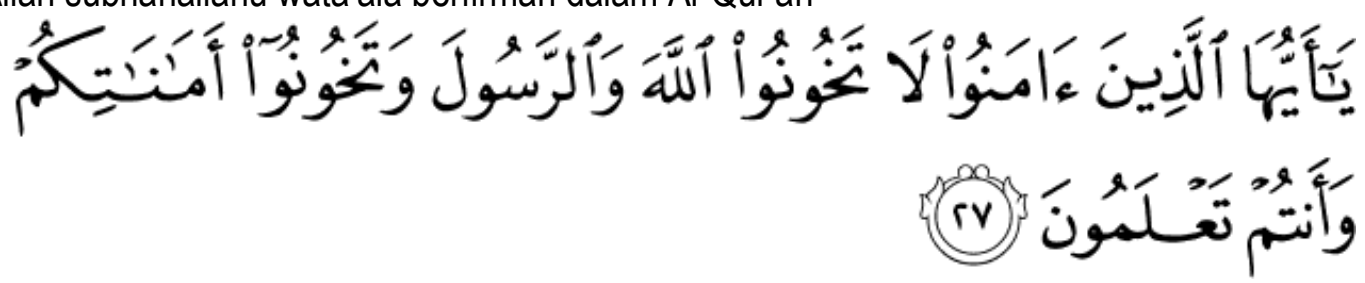

artinya: "Hai orang-orang yang beriman, janganlah kamu mengkhianati Allah dan Rasul (Muhammad) dan (juga) janganlah kamu mengkhianati amanat-amanat yang dipercayakan kepadamu, sedang kamu mengetahui". (QS Al-Anfaal, : 27).

Ketiga, para hendaknya hendaknya menyerahkan hasil atau keuntungan kerjanya kepada pemilik, karena hal ini merupakan bentuk menunaikan amanah atau tanggung jawab. Rasulullah salallahualaihi wasallam bersabda : "Seorang bendahara yang amanah, yang menunaikan apa yang diperintahkan kepadanya dengan senang hati, termasuk orang yang bershadaqah" Tidak boleh seorang pekerja agen mengambil sesuatu untuk dirinya karena itu merupakan pengkhianatan. Sebagaimana ia juga tidak boleh menyerahkan keuntungan kepada selain pemiliknya. Sesungguhnya itu adalah kezhaliman.

Keempat, tidak meminta upah diluar kesepakatan, kecuali pemilik ridho. Jika tidak ridho maka hanya ada dua pilihan, mencari kerja di tempat lain atau bersabar sambil berdo'a. Jika hubungan antara agen dengan pemilik bisa dijalankan sesuai dengan syariat Islam, maka akan terjadi hubungan kerja yang harmonis dan penuh persaudaraan. Semua ini akan menghasil keberkahan bagi keduanya.

\section{Simpulan}

Berdasarkan uraian di atas, ada beberapa hal yang harus dimiliki kedua belah pihak dalam menjalankan perjanjian kontrak, pertama mendahulukan tawakkal daripada akal nafsu, dan kedua memiliki akhlak yang baik. Dalam usaha selalu dihadapkan pada permasalahan matematis untung dan rugi. Dalam hal ini yang harus diyakini adalah bahwa muamalah dalam islam bukan 
masalah untung dan rugi namun lebih kepada menghidupkan syariat Allah dan mencari ridho Allah seperti firmanNya.

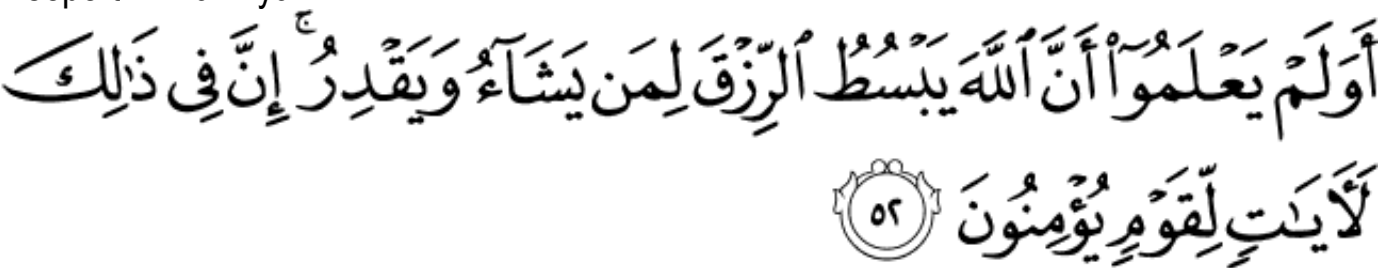

Dan tidakkah mereka mengetahui bahwa Allah melapangkan rezeki dan menyempitkannya bagi siapa yang dikehendaki-Nya? Sesungguhnya pada yang demikian itu terdapat tanda-tanda kekuasaan Allah bagi kaum yang beriman (QS, Az Zumar :52)

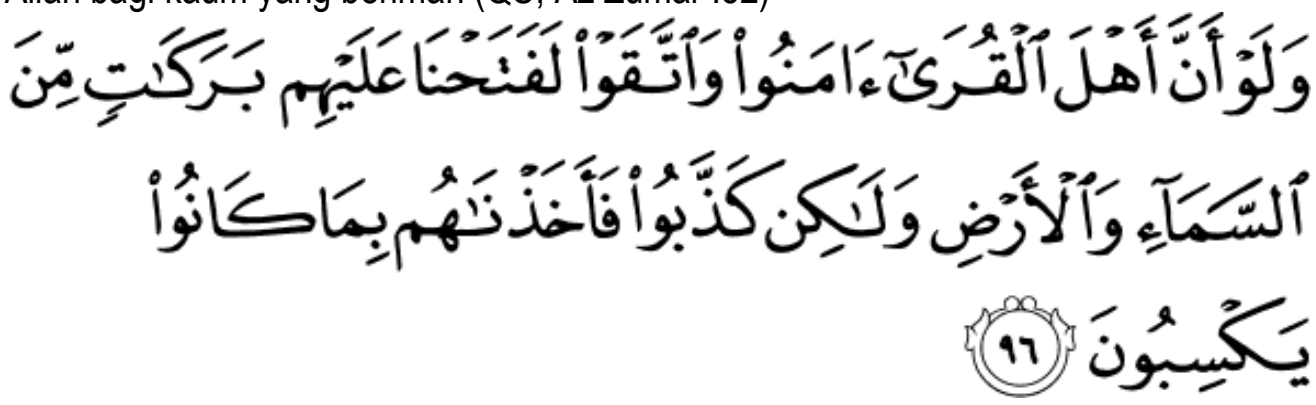

Artinya:

Jikalau sekiranya penduduk negeri-negeri beriman dan bertakwa, pastilah Kami akan melimpahkan kepada mereka berkah dari langit dan bumi, tetapi mereka mendustakan (ayat-ayat Kami) itu, maka Kami siksa mereka disebabkan perbuatannya. (QS. Al A'Raf: 96)

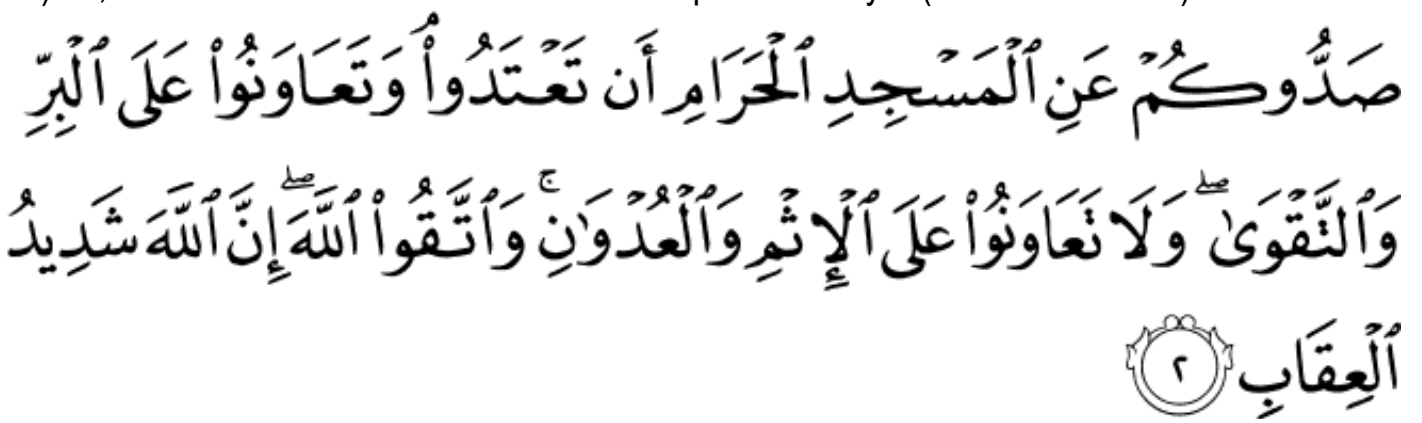

...Dan tolong-menolonglah kamu dalam (mengerjakan) kebajikan dan takwa, dan jangan tolongmenolong dalam berbuat dosa dan pelanggaran. Dan bertakwalah kamu kepada Allah, sesungguhnya Allah amat berat siksa-Nya. (QS. Al Maidah ayat 2)

Dalam ketiga ayat di atas penting sekali bagi pemilik dan agen memiliki sikap tawakal (bersandar) kepada Allah atas usaha yang dilakukan bersama setelah bersama-sama semaksimal mungkin memenuhi tanggungjawabnya. Baik pemilik maupun agen keduanya adalah "pekerja" Allah dan bahwa usaha yang dilakukan bersama dengan sungguh-sungguh merupakan satu hal yang kita serahkan kepada Allah, sedangkan rezeki merupakan hal lain yang merupakan hak Allah untuk menentukannya.

Hal selanjutnya yang sangat penting untuk dimiliki oleh principal dan agen dalam melakukan kerjasama adalah akhlak yang baik. Aisyah radiallhuanhu berkata bahwa ada sepuluh perkara yang termasuk akhlak yang paling mulia. Perkara ini kadang ada pada diri anak tetapi tidak terdapat pada diri ayahnya. Perkara tersebut terdapat pada diri hamba sahaya namun tidak terdapat pada diri tuannya. Perkara tersebut merupakan pemberian Allah ta'ala, dan Allah ta'ala mengaruniakan kepada siapasaja yang dikehendakiNya, yakni 1) Berbicara benar, 2) Berbuat jujur kepada orang lain, 3) Memberi kepada peminta-minta, 4) Membalas budi baik, 5) 
Menyambung tali silaturahhim, 6) Menjaga amanah, 7) Menunaikan hak tetangga, 8) Menunaikan hak kawan, 9) Menunaikan hak tamu, 10) dan induk dari semua itu adalah malu (Ihya Ulumiddin)(Zakariyya, 2006).

\section{DAFTAR PUSTAKA}

Alquran Al Karim

Baiman, S. (1990). Agency Research In Managerial Accounting : A Second Look *. Accounting Organizations and Society, 15(4), 341-371.

Isgiyarta, J (2010). Telaah Kritis Investasi Dalam Perspektif Islam. Jurnal Maksi, 10(2), 218-230. Jensen, M. C., \& Meckling, W. H. (1976). Theory Of The Firm : Managerial Behavior , Agency Costs And Ownership Structure Agency Costs And Ownership Structure. Journal of Financial Economic, 3(4), 305-360.

Kandahlawi, M. Y. (2006). Muntakhab Ahadits.pdf.

Zakariyya, M. (2006). Fadhail Sedekah.pdf. 